\title{
A New Application for the Goal Programming-The Target Decision Rule for Uncertain Problems
}

\author{
Helena Gaspars-Wieloch (D) \\ Department of Operations Research and Mathematical Economics, Institute of Informatics and Quantitative \\ Economics, Poznan University of Economics and Business, 61-875 Poznan, Poland; \\ Helena.gaspars@ue.poznan.pl
}

Received: 24 October 2020; Accepted: 9 November 2020; Published: 13 November 2020

check for updates

\begin{abstract}
The goal programming (GP) is a well-known approach applied to multi-criteria decision making (M-DM). It has been used in many domains and the literature offers diverse extensions of this procedure. On the other hand, so far, some evident analogies between M-DM under certainty and scenario-based one-criterion decision making under uncertainty (1-DMU) have not been revealed in the literature. These similarities give the possibility to adjust the goal programming to an entirely new domain. The purpose of the paper is to create a novel method for uncertain problems on the basis of the GP ideas. In order to achieve this aim we carefully examine the analogies occurring between the structures of both issues (M-DM and 1-DMU). We also analyze some differences resulting from a different interpretation of the data. By analogy to the goal programming, four hybrids for 1-DMU are formulated. They differ from each other in terms of the type of the decision maker considered (pessimist, optimist, moderate). The new decision rule may be helpful when solving uncertain problems since it is especially designed for neutral criteria, which are not taken into account in existing procedures developed for 1-DMU.
\end{abstract}

Keywords: goal programming; multi-criteria decision making under certainty; one-criterion decision making under uncertainty; scenario planning; neutral criteria; decision maker's nature

JEL Classification: C02; C25; C44; C53; C61; D81; D83; D84

\section{Introduction}

The goal programming (GP) is one of the methods applied to multi-criteria decision making (M-DM). This type of decision making is related to the situation where the decision maker (DM) assesses particular alternatives (courses of action, decision variants, options) on the basis of more than one criterion. Criteria are usually conflicting.

M-DM involves two groups of issues: Multiple Attribute Decision Problems (MADP) and Multiple Objective Decision Problems (MODP). In MADP the number of possible options is precisely defined at the beginning of the decision making process and the levels of considered attributes are assigned to each alternative (Singh et al. 2020). Within MODP the cardinality of the set of potential decision variants is not exactly known. The decision maker only knows the mathematical optimization model, i.e., the set of objective functions and constraints that create the set of possible solutions (Ding et al. 2016; Tzeng and Huang 1981). The goal programming is successfully used in the discrete and continuous version of M-DM, i.e., in MADP and MODP, respectively.

The goal programming was first applied by Charnes et al. (1955). Nevertheless, its name first appeared in Charnes and Cooper (1961). Although GP was developed many years ago, it is still applied to numerous theoretical and practical problems (Spivey and Hirokuni 1970; Spronk 1981; Vrat and Kriengkrairut 1986; Giokas 1997; Lin et al. 2009; Gaspars-Wieloch 2017a, 2018a; 
Gupta et al. 2018; Gür and Eren 2018; Ismail et al. 2019; Mensah and Rocca 2019; Aliasghari et al. 2020; Khan et al. 2020).

The idea of GP consists of assigning a goal (target value) to each criterion. These targets are supposed to be achieved. That means that the approach requires computing deviations from the goals both above and below the target. The last step of the algorithm is to minimize a weighted sum of unwanted positive and negative deviations. Note that weights signify the importance of particular criteria. The use of GP leads to a compromised solution.

It is important to realize that the goal programming is especially designed for problems where neutral criteria are considered—criteria are neither maximized nor minimized because they consist in reaching a specific value. This feature is extremely vital, since M-DM procedures have been mainly developed for maximized and minimized criteria, not for neutral ones (e.g., SAW method, TOPSIS, interactive programming, Pareto approach, Electre, max-min approach). The use of neutral criteria is quite frequent in solving real decision problems. They may be related to such attributes as the period of paying off the credit (the term of the loan), the rental time of office space, the duration of the project, the temperature level, the distance between two places, the number of rooms in a house, the surface of the plot or the level of precipitation.

The GP was initially formulated for M-DM under certainty (M-DMC), i.e., assuming that all the parameters of the decision problems are known. In subsequent years, this procedure has been extended to fuzzy multi-criteria problems (Ghaffar et al. 2020; Khan et al. 2020) or combined with other approaches for diverse purposes (Gaspars-Wieloch 2017a, 2018a; Giokas 1997; Lin et al. 2009).

In this paper we intend to apply the idea of the original GP to a new issue, which is possible because the structure of M-DM under certainty (M-DMC) is extremely similar to the structure of scenario-based 1-DMU, i.e., one-criterion decision making under uncertainty on the basis of scenario planning (SP). The second area is connected with situations in which the DM evaluates a given decision variant in terms of one objective function, but, due to numerous unknown future factors, the parameters of the problem are not deterministic. Instead of that a set of potential scenarios is available. These scenarios may be defined by experts, decision makers or by a person who is simultaneously an expert and a DM. "Scenario" means a possible way in which the future might unfold.

The scenario-based 1-DMU is investigated by many researchers and practitioners, since real economic decision problems (e.g., choice of investment projects, selection of marketing strategies, choice of technology, human resource management) are usually uncertain (Gaspars-Wieloch 2014b, 2014c, 2014d, 2015a, 2015d, 2017b, 2017c, 2018b, 2019b, 2020, 2021; Gaspars-Wieloch and Michalska 2016; Gilboa 2009; Ioan and Ioan 2011; Karvetski and Lambert 2012; Maciel et al. 2018; Pollack-Johnson and Liberatore 2005).

As it has been already mentioned, the aim of the paper is to develop a new application for the GP, i.e., to use its methodology in one-criterion decision making under uncertainty. Such an extension is desired since the existing methods formulated for 1-DMU are designed for maximized or minimized criteria (not for neutral ones), e.g., Bayes rule, Hayashi rule, Hurwicz rule, Savage rule, Wald rule (Hayashi 2006, 2008; Hurwicz 1952; Savage 1954, 1961; Wald 1950a, 1950b).

It is worth underlining that there are diverse uncertainty levels (Courtney et al. 1997; Waters 2011):

I Uncertainty with known probabilities (the DM knows the alternatives, scenarios, scenario probabilities and particular outcomes);

II Uncertainty with partially known probabilities (the DM knows the alternatives, scenarios, partial scenario probabilities and particular outcomes-probabilities may be given as interval values, sometimes scenarios are ordered according to their approximate chance to occur);

III Uncertainty with unknown probabilities (the DM knows the alternatives, scenarios, and particular outcomes-scenario probabilities are not known);

IV Uncertainty with unknown scenarios (the DM knows alternatives only). 
In the article the third level is investigated since in connection with the fact that the set of scenarios in SP does not need to be exhaustive, the use of probabilities seems to be unjustifiable (Michnik 2013; Stewart et al. 2013). Furthermore, von Mises $(1949,1962)$ adds that the probability of a single event should not be expressed numerically because probabilities only concern repetitive situations which are not frequent in real economic problems (innovative or innovation projects, turbulent times etc.).

In the list of possible uncertainty levels, the notion "outcome" appears many times. The words "outcome", "result", or "payoff" signify the effect gained by the DM if he or she selects a given option and a given scenario occurs. The outcomes may be estimated by means of different tools, e.g., econometric models (Deloite 2012), forecasting methods (Cherepovitsyn and Ilinova 2018) and simulations.

It is worth stressing that in this paper we focus on scenario planning as an uncertainty modelling tool, but of course, there are many other opportunities to handle uncertainty, e.g., fuzzy numbers, probabilities, probability-like quantities, or explicit risk measures. SP has got numerous advantages. First, contrary to the aforementioned approaches, it is easy to understand even for practitioners who have not got sophisticated mathematical skills. Second, it gives the possibility to analyze the problems in a more deterministic way than for example fuzzy numbers (Durbach 2014; Maciel et al. 2018; Schoemaker 1995). Third, thanks to SP the organizations are better prepared to handle new situations and promote proactive leadership initiatives as scenario planning recognizes technological discontinuities or disruptive events and includes them into long-range planning (Mietzner and Reger 2005).

In order to construct a decision rule for the scenario-based 1-DMU which refers to the methodology adopted in the goal programming for MCDM-C, the rest of the paper is organized as follows. Section 2 presents in detail the analogies between one-criterion decision making under uncertainty and multi-criteria decision making under certainty. So far, these analogies have not been revealed in the literature. The section also reminds subsequent steps of the goal programming. In the article we only investigate the discrete version of M-DM, i.e., MADM. The last part of this section is devoted to the description of a novel approach for 1-DMU, based on the GP (initially designed for multi-criteria decision making). We name the suggested method-Target Decision Rule (TDR). Section 3 uses illustrative examples to show how GP solves multi-criteria problems and how the new procedure may be applied to uncertain problems. The features of the suggested method are discussed in Section 4 . Conclusions are gathered in the last section.

The new 1-DMU procedure may bring significant advantages since it allows to consider criteria of any kind (maximized, minimized and neutral), hence to solve a larger number of decision problems than other decision rules do. Although the suggested method is formulated on the basis of the goal programming created for another issue (i.e., multi-criteria optimization), it is less complex than GP is, because this time the use of the normalization technique is redundant due to the specificity of 1-DMU (where only one criterion is taken into account during the option assessment).

\section{Materials and Methods}

The discrete multi-criteria problem can be presented in the form of a payoff matrix which contains possible alternatives, significant criteria, and outcomes for each pair: Option/criterion (Table 1). The interpretation of particular symbols used in the matrix is as follows: $n$-number of alternatives, $p$-number of criteria, $b_{k, j}$ - performance of criterion $C_{k}$ if option $A_{j}$ is selected. 
Table 1. Payoff matrix for the discrete M-DMC.

\begin{tabular}{cccccc}
\hline \multirow{2}{*}{ Criteria } & \multicolumn{5}{c}{ Alternatives } \\
\cline { 2 - 6 } & $\mathbf{A}_{\mathbf{1}}$ & $\ldots$ & $\mathbf{A}_{\mathbf{j}}$ & $\ldots$ & $\mathbf{A}_{\mathbf{n}}$ \\
\hline $\mathrm{C}_{1}$ & $\mathrm{~b}_{1,1}$ & $\ldots$ & $\mathrm{b}_{1, j}$ & $\ldots$ & $\mathrm{b}_{1, \mathrm{n}}$ \\
$\vdots$ & $\vdots$ & $\ddots$ & $\vdots$ & $\ddots$ & $\vdots$ \\
$\mathrm{C}_{\mathrm{k}}$ & $\mathrm{b}_{\mathrm{k}, 1}$ & $\vdots$ & $\mathrm{b}_{\mathrm{k}, \mathrm{j}}$ & $\vdots$ & $\mathrm{b}_{\mathrm{k}, \mathrm{n}}$ \\
$\vdots$ & $\vdots$ & $\ddots$ & $\vdots$ & $\ddots$ & $\vdots$ \\
$\mathrm{C}_{\mathrm{p}}$ & $\mathrm{b}_{\mathrm{p}, 1}$ & $\ldots$ & $\mathrm{b}_{\mathrm{p}, \mathrm{j}}$ & $\ldots$ & $\mathrm{b}_{\mathrm{p}, \mathrm{n}}$ \\
\hline \multicolumn{5}{c}{ Source: Prepared by the author. }
\end{tabular}

The payoff matrix representing the scenario-based 1-DMU problem is very similar (Table 2).

Table 2. Payoff matrix for the scenario-based 1-DMU.

\begin{tabular}{cccccc}
\hline \multirow{2}{*}{ Scenarios } & \multicolumn{5}{c}{ Alternatives } \\
\cline { 2 - 6 } & $\mathbf{A}_{\mathbf{1}}$ & $\ldots$ & $\mathbf{A}_{\mathbf{j}}$ & $\ldots$ & $\mathbf{A}_{\mathbf{n}}$ \\
\hline $\mathrm{S}_{1}$ & $\mathrm{a}_{1,1}$ & $\ldots$ & $\mathrm{a}_{1, \mathrm{j}}$ & $\ldots$ & $\mathrm{a}_{1, \mathrm{n}}$ \\
$\vdots$ & $\vdots$ & $\ddots$ & $\vdots$ & $\ddots$ & $\vdots$ \\
$\mathrm{S}_{\mathrm{i}}$ & $\mathrm{a}_{\mathrm{i}, 1}$ & $\vdots$ & $\mathrm{a}_{\mathrm{i}, \mathrm{j}}$ & $\vdots$ & $\mathrm{a}_{\mathrm{i}, \mathrm{n}}$ \\
$\vdots$ & $\vdots$ & $\ddots$ & $\vdots$ & $\ddots$ & $\vdots$ \\
$\mathrm{S}_{\mathrm{m}}$ & $\mathrm{a}_{\mathrm{m}, 1}$ & $\ldots$ & $\mathrm{a}_{\mathrm{m}, \mathrm{j}}$ & $\ldots$ & $\mathrm{a}_{\mathrm{m}, \mathrm{n}}$ \\
\hline \multicolumn{5}{c}{ Source: Prepared by the author. }
\end{tabular}

In Table 2 symbol $\mathrm{n}$ denotes the number of alternatives, $\mathrm{m}$ is the number of scenarios, $\mathrm{a}_{\mathrm{i}, \mathrm{j}}$ signifies the payoff obtained if options $A_{j}$ is selected and scenario $S_{i}$ occurs.

As we can observe, the analogy between the structures of both considered issues is evident. In both cases there is a set of potential options. As well, the set of significant criteria in M-DMC can correspond to the set of potential scenarios in 1-DMU. Additionally, the outcomes for each pair (alternative/criterion) may be related to payoffs for each pair (alternative/scenario).

However, it is worth underlining that in spite of the strong similarities between both matrices, the interpretation of data given in both tables is essentially different. Within M-DMC, if $A_{j}$ is selected, the DM is supposed to experience $p$ final outcomes, i.e., $b_{1, j}, \ldots, b_{k, j}, \ldots, b_{p, j}$, because particular decision variants are evaluated in terms of $p$ significant criteria. Within 1-DMU, if $A_{j}$ is chosen, the final outcome $\left(\mathrm{a}_{\mathrm{i}, \mathrm{j}}\right)$ is single and depends on the real scenario which will occur.

Now, let us analyze the GP algorithm for M-DMC. It consists of the following steps:

1. Define the set of alternatives, the set of criteria, the outcomes for each pair (alternative/criterion) and create a payoff matrix;

2. Define the target $\left(t_{k}\right)$ for each criterion. Minimal or maximal values are also possible. If a given target value is intermediate (i.e., higher than the minimal performance, but lower than the maximal performance), that means that the criterion connected with this goal is neutral for the decision maker;

3. Define the weight $\left(w_{k}\right)$ for each criterion. If the criteria are equivalent, the weights are equal;

4. If criteria are not expressed in the same scale and unit, normalize initial data by means of Equation (1) or (2) and generate a new payoff matrix. The first formula is designed for criteria which are arbitrarily treated as maximized (even if in a given problem a given criterion is 
neutral). The second formula can be applied to minimized criteria and criteria arbitrarily treated as minimized.

$$
\begin{aligned}
& b(n)_{k, j}=\frac{b_{k, j}-\min _{j} b_{k, j}}{\max _{j} b_{k, j}-\min _{j} b_{k, j}} \\
& b(n)_{k, j}=\frac{\max _{j} b_{k, j}-b_{k, j}}{\max _{j} b_{k, j}-\min _{j} b_{k, j}}
\end{aligned}
$$

5. If necessary, transform the desired levels (i.e., targets) into normalized ones: $t(n)_{k}$;

6. Compute the deviations (in absolute values) from the (normalized) targets for each (normalized) outcome (Equation (3) or (4)) and generate a deviation matrix:

$$
\begin{gathered}
d_{k, j}=\left|b_{k, j}-t_{k}\right| \\
d_{k, j}=\left|b(n)_{k, j}-t(n)_{k}\right|
\end{gathered}
$$

7. Calculate the weighted sum of deviations for each option (Equation (5)):

$$
G P_{j}=\sum_{k=1}^{p} w_{k} d_{k, j}
$$

8. Select the alternative with the minimal index $G P_{j}$.

As a matter of fact, the algorithm presented above concerns the Weighted Goal Programming. Other essential versions of GP are the Lexicographig Goal Programming and the Chebyshew Goal Programming (Gür and Eren 2018).

In last part of this section we are going to implement the idea of GP in a new area, i.e., the scenario-based 1-criterion decision making under uncertainty. Let us name the novel approach “Target Decision Rule for 1-DMU” (TDR). Here are its subsequent steps:

1. Define the set of alternatives, the set of scenarios, the outcomes for each pair (alternative/scenario) and create a payoff matrix;

2. Define the target $\left(t_{i}\right)$ for each scenario. If the target values are intermediate (i.e., lower than the maximal one within the whole matrix, but higher than the minimal one), that just means that the criterion used to evaluate particular decision variants is neutral;

3. Define the weight $\left(\mathrm{w}_{\mathrm{i}}\right)$ for each scenario. It does not represent the scenario importance (since the decision maker has no impact on the scenario which will ultimately occur), but it can describe the subjective chance of occurrence of particular scenarios. If the DM has no knowledge concerning particular scenarios, the weights may be equal (the same assumption is made within the Bayes rule). Alternatively, instead of weights for each scenario, the DM can declare his/her optimism coefficient $\beta$ which belongs to the interval $[0,1]$. Such a parameter is used for instance in the Hurwicz rule (Hurwicz 1952). The coefficient $\beta$ expresses the decision maker's nature, state of mind and soul, predictions concerning the future. It is equal to 0 for extreme pessimists (expecting the occurrence of scenarios with the worst outcomes) and 1 for extreme optimists (expecting the occurrence of scenarios with the best outcomes). $\beta$ can be estimated for the whole decision problem or separately for each alternative;

4. Compute the deviations (in absolute values) from the targets for each outcome (Equation (6)) and generate a deviation matrix:

$$
d_{i, j}=\left|a_{i, j}-t_{i}\right|
$$

5. Choose the final option on the basis of an existing decision rule (e.g., max-max rule, Wald rule, Hurwicz rule, Bayes rule) selected according to the DM's nature. 
As it can be seen, the suggested approach constitutes a hybrid of the goal programming developed for M-DMC and an existing decision rule formulated for uncertain problems with maximized or minimized criteria. Note that the deviation matrix obtained in step 4 should be treated like a cost matrix since each deviation is regarded as an unwanted result.

\section{Results}

In this section we present several simple examples allowing to:

- $\quad$ Reveal the existing analogy between the problems considered (M-DMC and 1-DMU);

- $\quad$ To understand the proposed method (TDR).

We start with a multi-criteria case solved by the original goal programming (Section 3.1) and then we examine diverse uncertain problems depending on the decision maker's nature (Sections 3.2 and 3.3).

\subsection{Goal Programming for $M-D M C$}

Let us assume that the managing director of a company is searching an attractive location for business (five potential places). He considers four criteria: amount of warehouse space (neutral $/ \mathrm{m}^{2}$ ), number of premises (neutral/pieces), annual cost of lease (minimized/thousand dollars), distance from the city center (neutral/km). Data are given in Table 3 (step 1).

Table 3. Initial data-example 1.

\begin{tabular}{cccccc}
\hline \multirow{2}{*}{ Criteria } & \multicolumn{5}{c}{ Alternatives } \\
\cline { 2 - 6 } & $\mathbf{L}_{\mathbf{1}}$ & $\mathbf{L}_{\mathbf{2}}$ & $\mathbf{L}_{\mathbf{3}}$ & $\mathbf{L}_{\mathbf{4}}$ & $\mathbf{L}_{\mathbf{5}}$ \\
\hline $\mathrm{C}_{1}$ & 2500 & 3400 & 1800 & 4000 & 2000 \\
$\mathrm{C}_{2}$ & 14 & 17 & 10 & 15 & 8 \\
$\mathrm{C}_{3}$ & 1700 & 2600 & 2000 & 2000 & 1300 \\
$\mathrm{C}_{4}$ & 7 & 4 & 10 & 20 & 18 \\
\hline \multicolumn{6}{c}{ Source: Prepared by the author. }
\end{tabular}

The targets for particular criteria are as follows: $t_{1}=3000, t_{2}=13, t_{3}=1300$ (i.e., the minimal one), $\mathrm{t}_{4}=10$ (step 2). The weights are equal to $\mathrm{w}_{1}=0.2, \mathrm{w}_{2}=0.3, \mathrm{w}_{3}=0.4, \mathrm{w}_{4}=0.1$ (step 3). Table 4 represents the normalized values (step 4 ). The normalization is necessary due to varied criteria scales and units. The performance degrees for criteria $C_{1}$ and $C_{2}$ were computed according to Equation (1), the remaining values on the basis of the Equation (2). In the case of a neutral criterion the choice of the formula is arbitrary, but it must be consistent with the choice made for the target linked to this criterion. Hence: $\mathrm{t}(\mathrm{n})_{1}=0.545, \mathrm{t}(\mathrm{n})_{2}=0.556, \mathrm{t}(\mathrm{n})_{3}=1.000, \mathrm{t}(\mathrm{n})_{4}=0.625$ (step 5).

Table 4. Normalized values-example 1.

\begin{tabular}{cccccc}
\hline \multirow{2}{*}{ Criteria } & \multicolumn{5}{c}{ Alternatives } \\
\cline { 2 - 6 } & $\mathbf{L}_{\mathbf{1}}$ & $\mathbf{L}_{\mathbf{2}}$ & $\mathbf{L}_{\mathbf{3}}$ & $\mathbf{L}_{\mathbf{4}}$ & $\mathbf{L}_{\mathbf{5}}$ \\
\hline $\mathrm{C}_{1}$ & 0.318 & 0.727 & 0.000 & 1.000 & 0.091 \\
$\mathrm{C}_{2}$ & 0.667 & 1.000 & 0.222 & 0.778 & 0.000 \\
$\mathrm{C}_{3}$ & 0.692 & 0.000 & 0.462 & 0.462 & 1.000 \\
$\mathrm{C}_{4}$ & 0.813 & 1.000 & 0.625 & 0.000 & 0.125 \\
\hline
\end{tabular}

Source: Prepared by the author.

The deviations are calculated on the basis of Equation (4), see Table 5 (step 6). 
Table 5. Deviations—example 1.

\begin{tabular}{cccccc}
\hline \multirow{2}{*}{ Criteria } & \multicolumn{5}{c}{ Alternatives } \\
\cline { 2 - 6 } & $\mathbf{L}_{\mathbf{1}}$ & $\mathbf{L}_{\mathbf{2}}$ & $\mathbf{L}_{\mathbf{3}}$ & $\mathbf{L}_{\mathbf{4}}$ & $\mathbf{L}_{\mathbf{5}}$ \\
\hline $\mathrm{C}_{1}$ & 0.227 & 0.182 & 0.545 & 0.455 & 0.455 \\
$\mathrm{C}_{2}$ & 0.111 & 0.444 & 0.333 & 0.222 & 0.556 \\
$\mathrm{C}_{3}$ & 0.308 & 1.000 & 0.538 & 0.538 & 0.000 \\
$\mathrm{C}_{4}$ & 0.188 & 0.375 & 0.000 & 0.625 & 0.500 \\
\hline \multicolumn{6}{c}{ Source: Prepared by the author. }
\end{tabular}

Source: Prepared by the author.

Now, it is sufficient to compute the weighted sums of deviations: $\mathrm{GP}_{1}=0.221, \mathrm{GP}_{2}=0.607$, $\mathrm{GP}_{3}=0.424, \mathrm{GP}_{4}=0.435, \mathrm{GP}_{5}=0.308$ (step 7), which enable to generate the following ranking: $\mathrm{L}_{1}, \mathrm{~L}_{5}$, $\mathrm{L}_{3}, \mathrm{~L}_{4}, \mathrm{~L}_{2}$ and indicate $\mathrm{L}_{1}$ as the best (step 8).

\subsection{Target Decision Rule for Extreme Pessimits or Optimists}

Let us assume that the managing director of a company is searching an attractive location for a social event which is going to be held on a 25 November $202 X$ (five potential places). The company tends to select the place according to the air temperature on that day $\left({ }^{\circ} \mathrm{C}\right)$. This criterion is crucial for the business success. Due to the lack of possibility to set deterministic temperature parameters, the company considers four possible scenarios. Both scenarios and possible temperature levels have been set by a meteorological and hydrological institute. Particular scenarios are quite different because the employees of the institute decided to take diverse factors into account (wind, hurricane, tornado, typhoon, precipitation, phase of the moon, windmills, sea currents, shape of the surface, height above sea level, etc.). The social event will be held in three years. Thus, the degree of uncertainty is very high. Data are gathered in Table 6 (step 1).

Table 6. Initial data-example 2.

\begin{tabular}{cccccc}
\hline \multirow{2}{*}{ Scenarios } & \multicolumn{5}{c}{ Alternatives } \\
\cline { 2 - 6 } & $\mathbf{L}_{\mathbf{1}}$ & $\mathbf{L}_{\mathbf{2}}$ & $\mathbf{L}_{\mathbf{3}}$ & $\mathbf{L}_{\mathbf{4}}$ & $\mathbf{L}_{\mathbf{5}}$ \\
\hline $\mathrm{S}_{1}$ & 4 & 16 & 0 & 4 & 20 \\
$\mathrm{~S}_{2}$ & 2 & 18 & 2 & -4 & 17 \\
$\mathrm{~S}_{3}$ & 16 & 11 & 12 & -5 & 10 \\
$\mathrm{~S}_{4}$ & 11 & 6 & 14 & 11 & 7 \\
\hline \multicolumn{6}{c}{ Source: Prepared by the author. }
\end{tabular}

The desired level of the daily air temperature belongs to the interval $\left[5{ }^{\circ} \mathrm{C} ; 10{ }^{\circ} \mathrm{C}\right]$, so $\mathrm{t}_{1}, \mathrm{t}_{2}, \mathrm{t}_{3}, \mathrm{t}_{4} \in$ $[5,10]$ (step 2). The next step of the algorithm (step 3) strictly depends on the decision maker's nature. In this subsection we investigate the case of extreme decision makers: Radical optimists and radical pessimists. Thus, the weight estimation is not mandatory. Step 4 involves the deviation calculation. The results are given in Table 7 . Note that in connection with the fact that the target is defined as an interval, Equation (6) is not applicable here. The deviations ought to be computed according to Equation (7).

$$
d_{i, j}=\left\{\begin{array}{cc}
0, \text { if } & a_{i, j} \in\left[t_{i}^{\text {min }}, t_{i}^{\text {max }}\right] \\
a_{i, j}-t_{i}^{\text {max }}, \text { if } & a_{i, j}>t_{i}^{\text {max }} \\
t_{i}^{\text {min }}-a_{i, j}, \text { if } & a_{i, j}<t_{i}^{\text {min }}
\end{array}\right.
$$

where $\mathrm{tin}_{\mathrm{i}}$ and $\mathrm{t}^{\max }{ }_{\mathrm{i}}$ denote the endpoints of the interval aforementioned. 
Table 7. Deviations—example 2.

\begin{tabular}{cccccc}
\hline \multirow{2}{*}{ Scenarios } & \multicolumn{5}{c}{ Alternatives } \\
\cline { 2 - 6 } & $\mathbf{L}_{\mathbf{1}}$ & $\mathbf{L}_{\mathbf{2}}$ & $\mathbf{L}_{\mathbf{3}}$ & $\mathbf{L}_{\mathbf{4}}$ & $\mathbf{L}_{\mathbf{5}}$ \\
\hline $\mathrm{S}_{1}$ & 1 & 6 & 5 & 1 & 10 \\
$\mathrm{~S}_{2}$ & 3 & 8 & 3 & 9 & 7 \\
$\mathrm{~S}_{3}$ & 6 & 1 & 2 & 10 & 0 \\
$\mathrm{~S}_{4}$ & 1 & 0 & 4 & 1 & 0 \\
\hline \multicolumn{6}{c}{ Source: Prepared by the author. }
\end{tabular}

Within step 5 the best strategy is selected. For an extreme pessimist, the use of the Wald rule is recommended. The Wald indices are equal to $W_{1}=6, W_{2}=8, W_{3}=5, W_{4}=10, W_{5}=10$, respectively. It is extremely important to adjust the Wald rule to the data gathered in Table 7 . These numbers are treated as costs. Therefore, instead of maximizing minimal values (such a procedure is characteristic for the Wald rule), it is required to minimize maximal values. Thus, an extreme pessimist should choose location $\mathrm{L}_{3}$.

In the case of decision makers being extreme optimists, the max-max rule is suggested. Normally, it consists in maximizing maximal values. Nevertheless, in our example this procedure has to be transformed to a min-min rule. The indices equal $\mathrm{M}_{1}=1, \mathrm{M}_{2}=0, \mathrm{M}_{3}=2, \mathrm{M}_{4}=1, \mathrm{M}_{5}=0$, respectively. Hence, the managing director may choose location $\mathrm{L}_{2}$ or $\mathrm{L}_{5}$.

\subsection{Target Decision Rule for Moderate Decision Makers}

The previous subsection was devoted to this category of decision makers who are not frequent in reality. Usually, people are moderate DMs. In such circumstances the uncertain problem with a neutral criterion may be also solved by means of the steps performed within the Target Decision Rule, but this time its step 3 is mandatory.

For moderate DMs the literature offers for instance the well-known Hurwicz rule. Let us assume that the managing director of the company declares that his/her optimism coefficient $\beta$ equals 0.7 . This means that the best value connected with a given alternative will be multiplied by 0.7 and the worst value related to this option is going to be multiplied by the pessimism coefficient equal to 0.3 . Thus, what is interesting is within step 3, instead of constant weights assigned to each row (it was the case of GP), some mobile weights are assigned. Note that in the Hurwicz rule it is assumed that the intermediate values as well as repetitive extreme values obtain zero weights. Let us assume that we still examine the problem presented in example 2 (Table 6, Section 3.2), but in order to compute the Hurwicz indices the deviations gathered in Table 7 are required:

$$
\begin{gathered}
\mathrm{H}_{1}=0.7 \cdot 1+0.3 \cdot 6=2.5, \mathrm{H}_{2}=0.7 \cdot 0+0.3 \cdot 8=2.4, \mathrm{H}_{3}=0.7 \cdot 2+0.3 \cdot 5=2.9, \mathrm{H}_{4}=0.7 \cdot 1+0.3 \cdot 10=3.7, \\
\mathrm{H}_{5}=0.7 \cdot 0+0.3 \cdot 10=3.0
\end{gathered}
$$

Usually, the Hurwicz rule consists in maximizing the weighted sum of the maximal and minimal value, but again, due to the fact that Table 7 represents unwanted results, the optimal strategy should minimize the sum aforementioned. That is why location $L_{2}$ is recommended.

The literature also offers a decision rule for DMs who have no knowledge on the chance of occurrence of particular scenarios. This is the Bayes rule (Laplace rule)-it assumes that each scenario has the same probability. This probability can be treated as a weight. The company is considering four scenarios (the data from example 2 are still analyzed), so the probability for each scenario is equal to $1 / 4=0.25$. Generally, the Bayes rule indicates the best solution on the basis of the maximal weighted sum, but here the location with the minimal index should be selected (because the measures take the unwanted deviations into account). The Bayes indices equal $\mathrm{B}_{1}=2.75, \mathrm{~B}_{2}=3.75, \mathrm{~B}_{3}=3.5, \mathrm{~B}_{4}=5.25$, $\mathrm{B}_{5}=4.25$, respectively. The company should select location $\mathrm{L}_{1}$. 


\section{Discussion}

In this section we are going to discuss some aspects in detail.

First, thanks to the comparison of the structure of both problems (M-DMC and 1-DMU) and the description of both algorithms (GP and TDR), one sees that the new approach has a very similar construction to GP. This similarity is visible especially in the first steps, but in some cases even the last steps (computation of the weighted sum of deviations and choice of the alternative with the lowest index) are analogical.

Second, the great advantage of TDR (in relation to GP) is the lack of necessity to normalize initial data. Such a facilitation results from the fact that within 1-DMU only one criterion is taken into consideration. Thus, the problem of different units and scales does not occur.

Third, it is worth describing the importance of weights in both approaches (GP for M-DMC and Target Decision Rule for 1-DMU). In the first case they represent the significance of particular criteria. They are declared at the beginning of the decision making process and they are the same for each payoff connected with a given criterion (a constant weight is assigned to all the outcomes from a given row of the payoff matrix). In the second case, the weight levels strictly depend on the DM's nature (predictions, expectations, attitude towards risk) and the chosen decision rule. As we have observed, for extreme decision makers weights are not necessary (formally, they exist-for one scenario the weight is equal to 1 and for the remaining ones the weights are equal to 0 ). For moderate DMs the weights may be equal for each scenario (if the DM has no reason to believe that one scenario is more likely to occur than another-Bayes rule) or different (if the DM declares his/her optimism coefficient-Hurwicz rule). However, these values are not entirely linked to each payoff connected with a given scenario. Usually, the distribution of scenario weighs is different for each alternative, because the extreme values (the highest and the lowest) related to particular options occur for different pairs of scenarios.

Fourth, the Target Decision Rule actually constitutes a hybrid of the goal programming and a selected uncertainty decision rule (the choice depends on the DM's nature). Hence, there are many variants of TDR. In the paper four versions have been mentioned:

1. TDR supported by the Wald method (Section 3.2);

2. TDR supported by the max-max method (Section 3.2);

3. TDR supported by the Bayes rule (Section 3.3);

4. TDR supported by the Hurwicz rule (Section 3.3).

Nevertheless, other hybrid versions are also possible. We recommend referring for instance to decision rules formulated in (Gaspars-Wieloch 2014a, 2015b, 2015c, 2016, 2017d, 2019a, 2020); Jagodziński (2014). As a matter of fact, the majority of them are modifications of diverse classical decision rules, but they have not got their drawbacks.

Fifth, in M-DMC it is obvious that the target value may be different for each row of the matrix since each goal level is related to a different criterion. In 1-DMU it seems that the target level should be the same for each scenario, because the alternatives are assessed in terms of one criterion. However, there is a possibility to diversify the target levels for instance in the case when the payoff ranges for particular scenarios are substantially varied. So, if the average level of payoffs connected with a given scenario is significantly higher/lower than the mean level of outcomes linked to other scenarios, the DM may increase/decrease his/her expectations in relation to this scenario.

Sixth, note that the literature already offers methods for 1-DMU where the reference point is used (Bleichrodt 2007; Gaspars-Wieloch 2015b, 2018a; Gaspars-Wieloch and Michalska 2016; Kahneman and Tversky 1979; Michalska and Kopańska-Bródka 2015; Schwartz et al. 2008; Tversky and Kahneman 1992). However, the target value has a totally different interpretation than the reference point has. The target is a value that the DM intends to reach (both positive and negative deviations are unwanted). The reference point indicates only a threshold on the basis of which relative 
gains and relative losses can be computed. Positive deviations are then wanted, and negative deviations are unwanted.

Seventh, in Section 2 the Target Decision Rule has been described for the case where the target is defined as a concrete value, but the example 2 presented in Section 3.2 allows us to realize that interval targets are also possible when solving real decision problems. That is why, Equation (7) has been additionally formulated in Section 3.

Eighth, in the paper we have assumed in example 2 that the scenarios are dependent, which means that if for instance scenario $S_{1}$ occurs, the outcomes achieved by the DM will be equal to $a_{1,1}, a_{1,2}, \ldots$, $\mathrm{a}_{1, j}, \ldots$ or $\mathrm{a}_{1, \mathrm{n}}$, depending on the selected alternative. When the scenarios are dependent the payoffs connected with a given option create a sequence (not a set) of values. Hence, the structure of the payoff matrix is extremely important. Nevertheless, the Target Decision Rule can be also applied to uncertain problems where the scenarios are independent-in such circumstances data do not need to be presented in the form of a payoff matrix. It suffices to generate a separate set of outcomes for each decision variant, and what is interesting, the cardinality of particular sets may be different! This is a great advantage of TDR, since in real economic decision problems the potential alternatives are sometimes so distinct that each of them depends on different scenarios.

Ninth, sometimes a single index is not sufficient to choose the final alternative. That is why, we recommend applying such tools as the standard deviation which may measure the dispersion of all the deviations. This measure is also used for instance in Ioan and Ioan (2011).

Tenth, we assumed in the analyzed example that the DM was making the decision individually. In such a case the declaration of the DM's nature is quite simple. When we are dealing with group decision making, the declaration aforementioned is more complex and time-consuming. However, uncertainty modelling is still possible thanks to additional tools (e.g., brainstorming, negotiation).

\section{Conclusions}

The paper contains the description of a novel approach (Target Decision Rule) which may be applied to uncertain one-criterion decision making (1-DMU). The procedure has been developed by analogy to the goal programming designed for multi-criteria optimization under certainty (M-DMC). So far, the existing analogies between M-DMC and 1-DMU have not been revealed in the literature.

The main advantages of the new method are:

- The possibility to consider neutral criteria in the decision problem (note that the neutral character of a given criterion may result from individual DM's expectations);

- The opportunity to declare both concrete targets and interval targets;

- The opportunity to adjust its steps to the decision maker's nature;

- The possibility to analyze problems with dependent and independent scenarios;

- Its simplicity in relation to the goal programming (in TDR the normalization is not mandatory).

The existing 1-DMU procedures have been formulated for maximized and minimized criteria. The formulation of TDR fills the gap which resulted from the lack of uncertain decision rules designed for neutral criteria.

Possible areas of application of the new method are numerous. They involve all the scenario-based uncertain problems where the criterion applied to assess particular options is neutral. Such criteria may be related for instance to the temperature level, the level of precipitation, the distance between two places, the number of rooms in a house, the surface of the plot, the period of paying off the credit (the term of the loan), the rental time of office space, the duration of the project. Hence, the Target Decision Rule may be useful in such domains as project management, selection of investment strategies, real estate market and banking market. Due to the fact that the algorithm does not require probability knowledge, the procedure may be also applied to innovative and innovation projects which significantly differ from previous businesses. The lack of necessity to refer to the probability calculus gives the possibility to analyze decision situations in very dynamic and turbulent times. 
The proposed procedure may have some limitations. The first one is connected with the inability of the decision maker to define his or her attitude towards risk (optimism coefficient). This obstacle can be eliminated thanks to the use of psychological tests. The second constraint results from the lack of payoff matrix on the basis of which further steps of the algorithm could be performed. Nevertheless, as it was underlined in the introduction, the Target Decision Rule, like other scenario-based decision rules, is only designed for 1-criterion optimization under uncertainty where the outcomes for each pair alternative/scenario may be estimated. The third limitation concerns group decision making. In this case the use of TDR is also possible, but each step of the algorithm may be more time-consuming. In connection with the fact that some analogies between multi-criteria decision making under certainty and one-criterion decision making under uncertainty have been revealed in this paper, possible future research directions could be connected with other potential adjustments of existing methods (ideas) formulated for one area to the second, analogical one.

Funding: This research received no external funding.

Conflicts of Interest: The author declare no conflict of interest.

\section{References}

Aliasghari, Parinaz, Behnam Mohammadi-Ivatloo, Mehdi Abapour, Ali Ahmadian, and Ali Elkamel. 2020. Goal programming application for contract pricing of Electric Vehicle Aggregator in Join Day-Ahead Market. Energies 13: 1771. [CrossRef]

Bleichrodt, Han. 2007. Reference-dependent utility with shifting reference points and incomplete preferences. Journal of Mathematical Psychology 51: 266-76. [CrossRef]

Charnes, Abraham, and William Wager Cooper. 1961. Management Models and Industrial Applications of Linear Programming. New York: John Wiley and Sons.

Charnes, Abraham, William W. Cooper, and Robert O. Ferguson. 1955. Optimal estimation of executive compensation by linear programming. Management Science 1: 138-51. [CrossRef]

Cherepovitsyn, Alexey Evgenievich, and Alina Alexandrovna Ilinova. 2018. Methods and tools of scenario planning in areas of natural resources management. European Research Studies Journal XXI: 434-46.

Courtney, Hugh, Jane Kirkland, and Patrick Viguerie. 1997. Strategy under uncertainty. Harvard Business Review 75: 66-79. [PubMed]

Deloite. 2012. Econometric Analysis for Scenario-Based Planning. Available online: https://deloitte.wsj.com/cfo/ 2012/09/04/a-cfos-guide-to-scenario-based-planning-using-econometrics/ (accessed on 20 October 2020).

Ding, Tao, Liang Liang, Min Yang, and Huaqing Wu. 2016. Multiple Attribute Decision Making based on cross-evaluation with uncertain decision parameters. Mathematical Problems in Engineering 2016: 4313247. [CrossRef]

Durbach, Ian N. 2014. Outranking under uncertainty using scenarios. European Journal of Operational Research 232: 98-108. [CrossRef]

Gaspars-Wieloch, Helena. 2014a. Modifications of the Hurwicz's decision rules. Central European Journal of Operations Research 22: 779-94. [CrossRef]

Gaspars-Wieloch, Helena. 2014b. Modification of the maximin joy criterion for decision making under uncertainty. Quantitative Methods in Economics 15: 84-93.

Gaspars-Wieloch, Helena. 2014c. On a decision rule for mixed strategy searching under uncertainty on the basis of the coefficient of optimism. Procedia Social and Behavioral Sciences 110: 923-31. [CrossRef]

Gaspars-Wieloch, Helena. 2014d. The use of a modification of the Hurwicz's decision rule in multi-criteria decision making under complete uncertainty. Business Management and Education 12: 283-302. [CrossRef]

Gaspars-Wieloch, Helena. 2015a. Innovative products and newsvendor problem under uncertainty without probabilities. In Proceedings of the 13th International Symposium of Operational Research SOR'15. Edited by Zadnik Stirn, Lidija, Janez Zerovnik, Mirjana Kljajic Borstnar and Samo Drobne. Lubljana: Slovenian Society Informatika, pp. 343-50.

Gaspars-Wieloch, Helena. 2015b. Modifications of the Omega ratio in decision making under uncertainty. Croatian Operational Research Review 6: 181-94. [CrossRef] 
Gaspars-Wieloch, Helena. 2015c. On a decision rule supported by a forecasting stage based on the decision maker's coefficient of optimism. Central European Journal of Operations Research 23: 579-94. [CrossRef]

Gaspars-Wieloch, Helena. 2015d. On securities portfolio optimization, preferences, payoff matrix estimation and uncertain mixed decision making. Contemporary Issues in Business Management and Education 2015: 1-11.

Gaspars-Wieloch, Helena. 2016. Resource allocation under complete uncertainty-Case of asymmetric payoffs. Zeszyty Naukowe. Organizacja i Zarządzanie/Politechnika Ślaska 96: 247-58.

Gaspars-Wieloch, Helena. 2017a. A decision rule based on goal programming and one-stage models for uncertain multi-criteria mixed decision making and games against nature. Croatian Operational Research Review 8: 61-76. [CrossRef]

Gaspars-Wieloch, Helena. 2017b. Innovative projects scheduling with non-renewable resources on the basis of decision project graphs. In Proceedings of the 14th International Symposium of Operational Research SOR'17. Edited by Zadnik Stirn Lidija, Janez Zerovnik, Mirjana Kljajic Borstnar and SamoDrobne. Lubljana: Slovenian Society Informatika, pp. 426-33.

Gaspars-Wieloch, Helena. 2017c. Innovative projects scheduling with scenario-based decision project graphs. In Contemporary Issues in Business, Management and Education 2017-Conference Proceedings. Vilnius: Vilnius Gediminas Technical University Press. [CrossRef]

Gaspars-Wieloch, Helena. 2017d. Newsvendor problem under complete uncertainty: A case of innovative products. Central European Journal of Operations Research 25: 561-85. [CrossRef] [PubMed]

Gaspars-Wieloch, Helena. 2018a. Podejmowanie Decyzji w Warunkach Niepewności-Planowanie Scenariuszowe, Reguty Decyzyjne i Wybrane Zastosowania Ekonomiczne. [Decision Making under Uncertainty-Scenario Planning, Selected Decision Rules and Selected Economic Applications]. Poznań: Wydawnictwo Uniwersytetu Ekonomicznego w Poznaniu.

Gaspars-Wieloch, Helena. 2018b. The impact of the structure of the payoff matrix on the final decision made under uncertainty. Asia Pacific Journal of Operational Research 35: 1850001. [CrossRef]

Gaspars-Wieloch, Helena. 2019a. Project Net Present Value estimation under uncertainty. Central European Journal of Operations Research 27: 179-97. [CrossRef]

Gaspars-Wieloch, Helena. 2019b. Role of scenario planning and probabilities in economic decisions problems-Literature review and new conclusions. In International Scientific Conference "Contemporary Issues in Business, Management and Economics Engineering". Vilnius: Vilnius Gediminas Technical University.

Gaspars-Wieloch, Helena. 2020. Critical analysis of classical scenario-based decision rules for pure strategy searching. Organization and Management Series 149: 155-65.

Gaspars-Wieloch, Helena. 2021. Scenario planning combined with probabilities as a risk management tool-Analysis of pros and cons. International Journal of Economics and Business Research. in press. [CrossRef]

Gaspars-Wieloch, Helena, and Ewa Michalska. 2016. On two applications of the Omega ratio: Max $\Omega \min$ and omega $(\mathrm{H}+\mathrm{B})$. Prace Naukowe Uniwersytetu Ekonomicznego we Wrocławiu 446: 21-36.

Ghaffar, Abdul, Abdul Razzaq, Md Hasan, Zubair Ashraf, and Mohammad Faisal Khan. 2020. Fuzzy goal programming with an imprecise intuitionistic Fuzzy Preference Relations. Symmetry 12: 1548. [CrossRef]

Gilboa, Itzhak. 2009. Theory of Decision under Uncertainty. New York/Cambridge: Cambridge University Press.

Giokas, Dimitrios. 1997. The use of goal programming and data envelopment analysis for estimating efficient marginal costs of outputs. Journal of the Operational Research Society 48: 319-23. [CrossRef]

Gupta, Srikant, Armin Fügenschuh, and Irfan Ali. 2018. A multi-criteria goal programming model to analyze the sustainable goals of India. Sustainability 10: 778. [CrossRef]

Gür, Şeyda, and Tamer Eren. 2018. Scheduling and planning in service systems with goal programming: Literature review. Mathematics 6: 265. [CrossRef]

Hayashi, Takashi. 2006. Regret Aversion and Opportunity-Dependence. Austin: Mimeo, University of Texas.

Hayashi, Takashi. 2008. Regret aversion and opportunity dependence. Journal of Economic Theory 139: 242-68. [CrossRef]

Hurwicz, Leonid. 1952. A Criterion for Decision Making under Uncertainty. Technical Report 355. Prince: Cowles Commission.

Ioan, Catalin Angelo, and Gina Ioan. 2011. A method of choice of the best alternative in the multiple solutions case in the games theory. Journal of Accounting and Management 1: 5-8. 
Ismail, Eman, Rashwan Mahmoud, and Nadia Makary. 2019. A generalized goal programming model for parsimonious robust clusterwise linear regression. Journal of Statistics and Management Systems 22: 51-71. [CrossRef]

Jagodziński, Jacek. 2014. The extended Hurwicz criterion for decision making in logistic applications. Zeszyty Naukowe Wyższej Szkoły Bankowej we Wrocławiu 1: 25-43.

Kahneman, Daniel, and Amos Tversky. 1979. Prospect theory: An analysis of decision under risk. Econometrica 47: 263-91. [CrossRef]

Karvetski, Christopher W., and James H. Lambert. 2012. Evaluating deep uncertainties in strategic priority-Setting with an application to facility energy investments. Systems Engineering 15: 483-93. [CrossRef]

Khan, Mohammad Faisal, Md Hasan, Abdul Quddoos, Armin Fügenschuh, and Syed Suhaib Hasan. 2020. Goal programming models with linear and exponential Fuzzy Preference Relations. Symmetry 12: 934. [CrossRef]

Lin, Hao, Sev Nagalingam, and Grier Lin. 2009. An interactive meta-goal programming-based decision analysis methodology to support collaborative manufacturing. Robotics and Computer Integrated Manufacturing 25: 135-54. [CrossRef]

Maciel, Leandro, Rosangela Ballini, and Fernando Gomide. 2018. Evolving fuzzy modelling for yield curve forecasting. International Journal of Economics and Business Research 15: 290-311. [CrossRef]

Mensah, Emmanuel Kwasi, and Matteo Rocca. 2019. Light robust goal programming. Mathematical and Computational Applications 24: 85. [CrossRef]

Michalska, Ewa, and Donata Kopańska-Bródka. 2015. The Omega function for continuous distribution. In Conference Proceedings, 33rd International Conference Mathematical Methods in Economics. Edited by David Martinčik, Julia Ircingowá and Petr Janeček. Plzeň: University of West Bohemia.

Michnik, Jerzy. 2013. Scenario planning + MCDA procedure for innovation selection problem. Foundations of Computing and Decision Sciences 38: 207-20. [CrossRef]

Mietzner, Dana, and Guido Reger. 2005. Advantages and disadvantages of scenario approaches for strategic foresight. International Journal of Technology Intelligence and Planning 1: 220-39. [CrossRef]

Pollack-Johnson, Bruce, and Matthew J. Liberatore. 2005. Project planning under uncertainty using scenario analysis. Project Management Journal 36: 15-26. [CrossRef]

Savage, Leonard J. 1954. The Foundations of Statistics. New York: John Wiley and Sons.

Savage, Leonard J. 1961. The foundations of statistics reconsidered. In Studies in Subjective Probability. Edited by Henry Kyburg and Howard Smokler. New York: Wiley, pp. 173-88.

Schoemaker, Paul J. H. 1995. Scenario planning: A tool for strategic thinking. Sloan Management Review 36: 25-40.

Schwartz, Alan, Julie Goldberg, and Gordon Hazen. 2008. Prospect theory, reference points and health decisions. Judgment and Decision Making 3: 174-80.

Singh, Anjali, Anjana Gupta, and Aparna Mehra. 2020. Matrix games with 2-tuple linguistic information. Annals of Operations Research 287: 895-910. [CrossRef]

Spivey, Allen W., and Tamura Hirokuni. 1970. Goal programming in econometrics. Naval Research Logistics Quarterly 17: 183-92. [CrossRef]

Spronk, Jaap. 1981. Goal programming. In Interactive Multiple Goal Programming. Dordrecht: Springer. [CrossRef]

Stewart, Theodor J., Simon French, and Jesus Rios. 2013. Integrating multicriteria decision analysis and scenario planning-Review and extension. Omega 41: 679-88. [CrossRef]

Tversky, Amos, and Daniel Kahneman. 1992. Advances in prospect theory: Cumulative representations of uncertainty. Journal of Risk and Uncertainty 5: 297-323. [CrossRef]

Tzeng, Gwo-Hshiung, and Jih-Jeng Huang. 1981. Multiple Attribute Decision Making, Methods and Applications. Lecture Notes in Economics and Mathematical Systems 186. New York: Springer.

von Mises, Ludwig. 1949. Human Action. A Treatise on Economics. Auburn: Ludwig von Mises Institute.

von Mises, Ludwig. 1962. The Ultimate Foundation of Economic Science. An Essay on Method. Princeton/Toronto/New York/London: D. van Nostrand Company, Inc.

Vrat, Prem, and Charoen Kriengkrairut. 1986. A goal programming model for project crashing with piecewise linear time-cost trade-off. Engineering Costs and Production Economics 10: 161-72. [CrossRef]

Wald, Abraham. 1950a. Basic ideas of a general theory of statistical decisions rules. In Selected Papers in Statistics and Probability. New York: McGraw-Hill, pp. 656-68. 
Wald, Abraham. 1950b. Statistical Decision Functions. New York: Wiley.

Waters, Donald. 2011. Supply Chain Risk Management. Vulnerability and Resilience in Logistics, 2nd ed.London: Kogan Page.

Publisher's Note: MDPI stays neutral with regard to jurisdictional claims in published maps and institutional affiliations.

(C) 2020 by the author. Licensee MDPI, Basel, Switzerland. This article is an open access article distributed under the terms and conditions of the Creative Commons Attribution (CC BY) license (http://creativecommons.org/licenses/by/4.0/). 